\title{
No Need to Get Emotional? Emotions and Heuristics
}

\section{Introduction}

It is a widely-shared view that values are essentially linked to or dependent on emotions. Call this view the Dependence Thesis. Here are some general statements of the Dependence Thesis:

"The claim is that evaluation, and in particular moral evaluation, is somehow grounded in human sentiment." (D’Arms \& Jacobson 2000, 722)

"[A]ccording to many philosophies value is to be understood in terms of emotions." (Mulligan 2010, 475)

"The final sentence, it is probable, which pronounces characters and actions amiable or odious, praise-worthy or blameable; that which stamps on them the mark of honour or infamy, approbation or censure... depends on some internal sense or feeling, which nature has made universal in the whole species." (Hume 1975, 173)

These statements reveal little about the exact nature of the supposed link between values and emotions. What I am interested in this paper are the epistemic aspects of this link. For even if one believes that emotions present or give access to values, and believes further that this is a crucial fact about both emotions and values, one can ask how reliable or trustworthy emotional presentations of values may be. It could even be true that emotions provide what is in some sense a unique or privileged access to evaluative properties while not presenting these properties in a particularly reliable or trustworthy fashion.

In this paper, I intend to approach this epistemic issue by asking two related questions. First, how exactly do emotions latch onto or track values? And second, how well suited are emotions to detecting, learning or finding out about values?

To answer the first question, I will put forward what I call the heuristics-model of emotions. This is a model of emotions as a sui generis biological system subserving heuristic functions. It is meant to provide the basic framework for understanding the epistemic role of emotions with regard to value. This model is used then to answer the second question. If emotions are indeed heuristics of value, then it follows that emotions can be an important and useful source of information about value. Moreover, they will 
also be special in terms of how they deliver that information about value. However, they will not be epistemically superior in the sense that emotions will not be the highest court of appeal for the justification of axiological beliefs.

Call the highest-court-of-appeal-view the Epistemic Dependence Thesis (EDT). The negative objective of this paper is to reject EDT as here defined. The positive objective is to defend the heuristics-model. Further, I hope to show that EDT is incompatible with the heuristics-model and so the positive and negative objectives are interrelated. ${ }^{1}$

I will begin with the positive objective proceeding as follows. In Section 2, I will present the heuristics-model of emotions. Then Section 3 will review empirical evidence bearing on the heuristics-model. I will argue that this evidence supports the heuristics-model or at the very least does not appear to be inconsistent with it.

Section 4 begins to tackle the negative objective by making EDT more precise. It will be seen that this clarification is important because EDT, which I take to be the highest-courtof-appeal-view, is easily confused with different ideas regarding emotions as an epistemic resource such as, for example, that emotions are statistically more likely to be correct than evaluative beliefs. It will be shown that the heuristics-model is not incompatible with the latter view and can even be read as positively supporting it. It is EDT properly understood, namely as the highest-court-of-appeal-view, that I seek to reject and that I take the heuristics-model to be incompatible with.

Having thus clarified EDT and its relation to the heuristics-model, I will go on in Section 5 to apply the heuristics-model to celebrated cases from the philosophy of emotions literature. I argue that while the heuristics-model offers a good explanation of what goes in such cases, advocates of EDT (properly understood) will have a hard time accounting for the same phenomena. I will also try to show that the conclusions drawn from special cases generalize. The conclusion of the paper serves to demonstrate that skepticism about EDT is compatible with a continued emphasis on the importance of emotions in first-order normative ethics.

1 Of course, some may doubt EDT without accepting the heuristics-model. I believe that some of the arguments to be put forward in the following will appeal to these people as well. 


\section{The emotions-as-heuristics hypothesis}

As the basic framework for understanding the epistemic function of emotions with regard to value, I propose to model emotions as a complex sui generis biological system subserving heuristic functions. I will call this the emotions-as-heuristics-hypothesis and the corresponding model the heuristics-model of emotions.

Heuristics are mental short cuts or rules of thumb. What makes heuristics special from an epistemic point of view is how they work. The basic underlying mechanism of heuristicsbased thought-processes is substitution. The "target attribute" is substituted by a "heuristic attribute" which is easier to handle (Kahneman \& Frederick 2002). The epistemic task is carried out using this heuristic attribute rather than the original target attribute.

The mechanism of substitution enables rapid reactions when time and information are scarce: heuristics-based thinking is "fast and frugal" (Gigerenzer et al. 1999). These reactions are perfectly adequate to and adaptive in many natural and social environments so heuristics tend to work well in many cases, sometimes even significantly outperforming systematic, all-things-considered judgements (Gigerenzer \& Goldstein 1996; Czerlinski, Gigerenzer \& Goldstein 1999). However, when overgeneralized, heuristics can lead to flagrant errors of fact as well as to unacceptable normative judgments in various legal, moral, political and other practical contexts (Sunstein 2003; Sunstein 2005; Kahneman 2011).

To offer just a simple example, in assessing the risk of travelling by plane many people rely on the "availability heuristic" (Sunstein 2005, 532). ${ }^{2}$ That is, people think about the dangers of flying on the basis of widely reported and therefore memorable examples of airplane crashes instead of relying on statistical figures (sometimes even when these figures are readily available and sometimes even after having consulted these figures). In short, they substitute salience and familiarity for frequency and so they reach a false conclusion as regards the likelihood of plane crashes.

In agreement with most of the literature, I use the term "heuristic" quite comprehensively here. This usage is comprehensive in two senses. First, it can cover all kinds of thought-processes that differ from controlled, reflective reasoning and make use of

2 Other basic heuristics are "representativeness" and "anchoring", see Sunstein 2003, 752 summarizing the seminal works on the subject by Kahneman and Tversky. 
the mechanism of substitution. ${ }^{3}$ The difference is manifested in a number of empirical characteristics. Heuristic thought-processes are said to be "spontaneous, intuitive, effortless, and fast" whereas reflective thinking is "deliberate, rule-governed, effortful, and slow" (Kahneman \& Frederick 2002, 49). ${ }^{4}$ According to dual-process theories, these two ways of thinking stand for two distinct cognitive systems (System 1 and System 2) with different evolutionary histories and neural architectures (Damasio 1994; De Sousa 2010; Kahneman 2011).

Second, the usage is comprehensive in that it refers to "inferences about unknown aspects of the environment" based on information from one's memory and/or from one's environment (Gigerenzer \& Goldstein 1996, 650, 653) as well as more generally to "decision-making processes that reliably generate rational behaviour in relevant environments" (Hurley 2005, 587). In short, heuristics are specific epistemic procedures that generate reasons for beliefs, both evaluative and factual.

All in all, therefore, a "heuristics-heuristic" may work best to identify heuristics: we are dealing with a heuristic whenever "a difficult question is answered by substituting an answer to an easier one" (Kahneman \& Frederick 2002, 50). ${ }^{5}$ Now, my suggestion is that the epistemic function of emotions with regard to value is heuristical. That is, characteristic emotional responses — fear, anger, guilt, blame, indignation, etc. — are used as mental short cuts in normative evaluations. This is the gist of the heuristics-hypothesis.

Take guilt, for example. In terms of the heuristics-hypothesis, guilt is a heuristic which functions as follows: if I feel guilt about what I have done I will typically move to the conclusion that I must have done wrong. I will do so in a rapid, spontaneous and effortless manner. In short, my feeling of guilt will be an important heuristic cue when I normatively evaluate my action. The main reason for relying on this heuristic cue is the same as before. Focusing on the emotional response is easier than to attempt to make a systematic, all-things-considered judgement. ${ }^{6}$

\footnotetext{
3 So this usage leaves room for a more elaborate taxonomy of different sub-categories of heuristics (see Weber \& Ancker 2005, 563): narrative heuristics, affective heuristics, etc.

4 There is room for debate about how essential these characteristics are. For example, reflective thinking can be extremely fast and sometimes quite effortless and spontaneous.

5 However, it is important to steer clear of two potential pitfalls. First, heuristics-based thinking should not be contrasted with consequentialist or utilitarian thinking. A consequentialist or utilitarian approach can be heuristics-based or use reflective reasoning, and so can a deontological approach. The distinction between the two kinds of thought-processes is content-neutral. Second, whether a thought-process is rule-governed or not is orthogonal to whether it is heuristics-based or reflective. Heuristics can be rules, but need not be. And conversely, reflective thinking can rely on rules and principles. An important consequence of this is that moral principles are not necessarily heuristics, pace Bartsch \& Wright 2005.

6 It may be objected that this example is problematic because the feeling of guilt more often follows the belief that I have done wrong than the other way round. I seriously doubt whether this true as a matter of empirical fact. Whatever the case may be, as I make it clear in Section 3.1 below, the heuristics-hypothesis can easily
} 


\section{Defending the heuristics-model: empirical findings}

The heuristics-model is both philosophically plausible and is consistent with empirical scientific evidence. I will now summarize the evidence coming from empirically-oriented emotion research at the intersection of psychology, neuroscience, cognitive science, and evolutionary anthropology. However, we also have reason to adopt the heuristics-model because it offers the right framework to characterize the epistemic link between emotion and value. I will go on to discuss these philosophical issues in Sections 4 and 5 . $^{7}$

\subsection{Experimental psychology}

It has been repeatedly demonstrated that affective valence associated with objects or events will substantially influence people's judgments and decisions regarding those objects or events (Murphy \& Zajonc 1993). These findings show that affect influences judgments, preferences and choices whether or not the affect is consciously felt, and even if the affective state in question is a mere emotional arousal involving no discernible cognitive activity (Kunst-Wilson \& Zajonc 1980; Zajonc 1980).

Although the finding that emotions need not involve any cognitive activity - let alone structured evaluative judgments (pace Nussbaum 2001) - has important philosophical implications (see Prinz 2004), ${ }^{8}$ the idea in itself that emotions and other affective states can influence reason is an age-old commonplace. More novel is evidence that when people make judgments or decisions they directly rely on their emotions for information and evaluative cues (Damasio 1994; Slovic et al. 2002; Sunstein 2003).

This finding can account for various at first sight puzzling patterns of behaviour. For example, it has been suggested that people use affective tagging to render information meaningful. If some piece of information attracts no emotional response, then people will find it difficult to assess its importance and relevance. Among others, this could explain

accommodate the fact that emotional reactions sometimes follow upon evaluative judgments rather than precede them.

7 Naturally, the relationship between empirical emotion research and the philosophy of emotion is a two-way street, see Prinz 2004, 26-30; De Sousa 2010; Perler 2011, 11-13.

8 This view is sometimes referred to as the affective primacy paradigm. It is important to note that the heuristics-model defended here is not dependent on the truth or falsity of this paradigm. I will come back to this point later on. 
people's often peculiar attitudes towards risk and probability as well as their surprising assessments of potential outcomes when deciding on future policies (Finucane et al. 2000).

Thus people are notoriously insensitive to distant or slowly accumulating dangers banally but powerfully demonstrated by the case of smoking. It is argued that this is because these remote threats elicit no affective responses and so we find it difficult to factor them into our deliberative processes. By the same token, if a certain possible outcome triggers an immediate and intense emotional response, then it will loom very large in our thinking about what course of action to choose regardless of how this outcome otherwise compares with other outcomes in terms of probability, risk and potential benefits. To quote only one of many convergent findings, it was observed that people's perceptions of risk and risk-controlling policies were "strongly linked to the degree to which a hazard evoked feelings of dread. Activities associated with cancer are seen as riskier and more in need of regulation than activities associated with less dreaded forms of illness, injury, and death (e.g., accidents)." (Slovic et al. 2002, 410). It has also been observed that time-pressure increases the tendency to rely on such emotion-based assessments instead of reflective evaluations (Finucane et al. 2000; Slovic et al. 2002). This is exactly what the heuristicsmodel would predict.

There is evidence too that characteristic kinds of emotional responses play such a heuristic role in more narrowly normative and moral evaluations and decisions as well. For example, it has been found that people's views on appropriate punishment (in terms of severity, etc.) for wrongdoing is governed by a so-called "outrage heuristic" which dictates that "penalties should be a proportional response to the outrageousness of the act" (Sunstein 2005, 538; see also Kahneman \& Frederick 2002, 49, 63). Similarly, a "revulsion heuristic" frequently governs people's responses to questions of sexual morality. We could call this an "it's just disgusting!" heuristic (Sunstein 2005, 540). In fact, the impact of revulsion can be so strong that it can outweigh even one's best judgment to the contrary as cases of "moral dumbfounding" show (Haidt 2001, 814).

It is safe to predict that other emotions play similar heuristic functions. Thus I hypothesize that future research could demonstrate how a "shame heuristic" or "blame heuristic" impacts in practice on people's judgments of shamefulness or blameworthiness. Before turning to favourable evidence from other disciplinary areas, however, it is worth pausing to flesh out the picture drawn so far about the involvement of emotions in the execution of various epistemic tasks. The first question concerns the place of emotions in the relevant epistemic processes. The second issue throws light on the structure of the affective heuristics themselves. 
So, first, the evidence cited is compatible with two different conceptions regarding how emotions are embedded in thought-processes. One of these is that emotions themselves function as heuristics. On this conception, people rely on their affective states directly to settle various factual or normative questions. As Sunstein puts it, people "consult their affective reactions" (Sunstein 2005, 568 - italics mine). In other words, the affective response will be a direct epistemic input into the deliberative process and will be used to justify one's answer to the factual or normative question one is facing.

However, on an alternative conception, the role of emotions in the relevant epistemic processes is causal rather than justificatory. On this conception, the use of certain heuristics is causally triggered by the subject's affective response or state. The idea here is that emotional propensities incline or cause human beings to rely on certain kinds of heuristics. So, for example, the emotion of fear would not itself be a heuristic but rather part of the causal explanation why people rely on certain heuristics (e.g., availability) to assess what is fearsome. ${ }^{9}$

The two conceptions do not seem to be mutually exclusive and both are compatible with the heuristics-model. However, in some cases emotions clearly function as heuristics and not just triggering causes of cognitive heuristic processes. For one thing, emotional responses can also follow upon evaluative judgments rather than precede them. For example, it is possible that I come to regard my action as morally objectionable after reflecting upon it and this reflection prompts my feelings of guilt. So emotions cannot always be triggering causes. ${ }^{10}$ In any case, there is also ample empirical evidence of direct justificatory reliance on affective heuristics. ${ }^{11}$

9 How would this causal explanation go in this particular case? It could be the case that when people experience fear they generally tend to switch to heuristic thinking. This is because feeling the emotion creates a sense of emergency or at least urgency prompting the shift from the reflective to the heuristic thoughtprocess. Such causal explanations can be plausibly given for other emotions as well. They amount to general motivational explanations of the causal link between emotions and heuristics. However, consistent with this general link, there may also be specific causal connections between emotions and certain heuristics such as the availability heuristic as noted in the main body of the text above. For example, it could be argued that experiencing fear on a certain occasion increases the availability of past frightening events in one's memory. This in turn could lead one to overestimate the significance of such events and lead one to conclusions one would reject upon reflection. For the discussion of a similar hypothesis about a putative causal link of this kind between experiences happiness and sadness, on the one hand, and specific heuristics, on the other, see Schwarz \& Clore 1983, 518

10 Lazarus (1984) argues that emotions are always consequent upon such judgments. By contrast, the claim above is only that this is sometimes the case. Note that in those cases too when emotions are consequent upon judgments, the former can be said to play a heuristic role. Emotions have a back-up function in such cases serving to corroborate the evaluative judgment.

11 See esp. Schwarz \& Clore 1983 explicitly addressing the question whether affect merely prompts reliance on certain cognitive heuristics, e.g., the availability-heuristic, or has a direct "informational function" as well. The conclusion reached is that affective states can themselves function as heuristics (see esp. 518). Admittedly, the article cited focuses on moods rather than emotions, but there is no reason not to extend its conclusions to emotions proper as well. 
Second, as regards the structure of emotional responses it is worth noting that the heuristics-model is intended to remain neutral in the dispute among judgmentalists, quasijudgmentalists, and anti-judgmentalists in the philosophy of emotion, i.e., regarding the question whether a given emotion necessarily involves a constitutive evaluative judgment or not (see D'Arms \& Jacobson 2003). Further, it is also intended to remain neutral in the closely related debate in empirical emotion research as to whether emotions can occur without any accompanying cognitive activity at all (this is the debate about the already mentioned affective primacy hypothesis, see Prinz 2004, esp. 33-41).

The heuristics-model need not be committed to either side in these debates. If emotions do not involve constitutive evaluative judgments, only representations of non-conceptual evaluative concerns (Tappolet 2000; D’Arms \& Jacobson 2003; Döring 2010), then the epistemic role of emotions in thought-processes will be closer to that played by noninferential, non-conceptual perceptual inputs. On this picture, emotional responses form the heuristic basis of the evaluative judgments in ways relevantly similar to how we rely on the representational content of our perceptions when making perceptual judgments (Crane 1992; Tappolet 2000; Döring 2010, 293).

If, on the other hand, emotional responses necessarily involve the use of evaluative concepts, then it is plausible to treat these emotional responses as similar to straightforward cognitive judgments. No matter which structural account is right, however, emotional responses can be treated as providing reasons for beliefs and so can be plausibly taken to perform a heuristic function.

\subsection{Evolutionary accounts}

The heuristics-model sits well with standard evolutionary accounts of the adaptive value of emotions. Two important claims of such accounts are worth emphasizing here. First, that emotions - or at least basic emotions such as fear, anger, sadness or disgust - have evolved to deal with what Paul Ekman has called "fundamental life-tasks" (Ekman 1992). Emotions have helped to meet various challenges and threats human beings tended to face in their natural environments (Damasio 1995, 24). Further, emotions can enhance coordination among human beings and so have also helped humans to cooperate to better meet those environmental challenges together (Gibbard 1990; D’Arms 2005, 10). 
Second, there is considerable agreement that phylogenetic history has hard-wired basic emotional propensities in human beings. What exactly has been hard-wired is subject to dispute. At the same time, it is safe to say that patterns of emotional responsiveness that we can observe human beings to display today have been fixed by our distant evolutionary past to a great extent (Tooby \& Cosmides 1990; Damasio 1995; D’Arms and Jacobson 2003, 138).

These evolutionary accounts significantly increase the plausibility of the heuristics-model. Thus they offer the evolutionary background for what, according to the heuristics-model, emotions can do for us: provide quick-and-ready salient evaluative cues in standard situations when there is no time or no (perceived) need to undertake a more detailed cognitive assessment. But also these evolutionary accounts appear to converge with the heuristics-model as to what emotions cannot do for us. As phylogenetically hard-wired response-mechanisms, emotions are too rigid to track fine-grained evaluative features of situations which require us to make normative judgments or decisions. These positive and negative results already foreshadow the claims to be made in Sections 4 and 5 about the epistemic implications of the heuristic model and specifically about its incompatibility with EDT.

\subsection{Neuroscience}

In his comprehensive account of experimental research findings on the neurobiology of emotions, Damasio (1994) argues that emotions are geared primarily towards tracking actual or potential changes in one's own body. So even when tracking is conscious (which it may not be), the felt emotion need not involve any substantial cognitive-evaluative processing. ${ }^{12}$ This happens in the case of what Damasio calls "primary emotions" which involve responses to external stimuli coming from the external world or one's body in a hardwired, "pre-organized fashion". 13

It is true that there is a necessarily cognitive-evaluative component in the case of what Damasio calls "secondary emotions". These are "cognitively sharpened" emotions personalized through the individual's experiences in life. They can be typical (e.g.,

12 At least it need not involve any sort of conscious, conceptual processing. As LeDoux (1995) makes it clear, however, this does not mean that emotions involve no processing whatsoever. They can still involve sensory information processing and "processing that occurs in complex association areas of cortex in the frontal lobes or hippocampus." (225) LeDoux warns, however, that "just because emotion involves information processing this does not mean that emotion is cognition." (226)

13 For a detailed account of the neural organization of the fear system, see LeDoux 1995. 
homesickness) or highly idiosyncratic (e.g., “tenure-denial anger”) (D’Arms \& Jacobson 2003).

However, it is crucial to note two things here. First, in Damasio's portrayal this cognitiveevaluative process takes place prior to the emotional response. What happens is that a given situation, imagined or real, is cognitively evaluated and this cognitive evaluation triggers an emotional response whereby how one reacts emotionally to a certain cognitive evaluation will be in part determined by one's acquired and to some extent idiosyncratic emotional dispositions. The upshot is that the secondary emotion is consequent upon and does not form part of the cognitive-evaluative process. Second, Damasio insists that even the secondary, personalized emotional dispositions are obtained under the influence of primary, that is, hard-wired emotional response mechanisms (Damasio 1994, 136; Damasio 1995, 22).

It is safe to portray this data as consistent with the heuristics model. In fact, these findings help us draw a general picture about what emotions can and cannot do as an epistemic resource (even beyond our specific concern in this paper). What this picture reveals is that emotions are in general important ways of collecting information about changes in our own bodies and in the world and are crucial in translating this information into bodily reactions. But emotions subserve specific and to a large extent evolutionarily hardwired purposes. Because of this, emotions track a fairly restricted range of stimuli and so deliver only a special kind of information. Moreover, even the process by which emotions deliver that kind of information is relatively fixed and "pre-organized".

But what about Damasio's celebrated thesis that emotion and reason are in some important sense inseparable (Damasio 1994)? This thesis is based on the repeatedly confirmed observation that the breakdown of basic emotional capacities due to some unambiguously localizable physical impairment of the brain is responsible for certain patients' inability to reason and deliberate normally. It appears that emotional responsiveness and practical rationality go hand-in-hand. Doesn't this finding contradict the heuristics-hypothesis after all?

There is no reason to accept this negative conclusion in my view. For one thing, it does not follow from the correctness of the general claim about the involvement of emotions in reasoning processes that drawing on an occurrent emotion when making a particular decision or judgment in a given situation will always improve the rationality of that decision or judgment. ${ }^{14}$ So there is an important type-token distinction to be made here. ${ }^{15}$

14 As Damasio would certainly agree, see for example Damasio 1994, xii. 
Even more importantly, however, Damasio's thesis is perfectly compatible with the view that the contribution of emotions to reasoning processes is of a heuristic character. We need emotions and feelings (just as we need other, non-affective heuristics) because they frequently set us off in the right direction and make us do the right thing. Emotions can prepare the ground, as it were, for a more detailed cognitive assessment.

In addition, these findings once again prefigure what I want to say in Sections 4 and 5 about the epistemic implications of the heuristic model and specifically about its incompatibility with EDT. While emotions contribute useful information about axiological properties, empirical data about the neural organization of emotions does not suggest that the information emotions provide about value would be especially reliable or trustworthy. ${ }^{16}$

\section{The heuristics-model and the Epistemic Dependence Thesis}

It is time to take on the negative objective of this paper. This is to question the plausibility of EDT. In order to successfully accomplish this goal, we need to make EDT more precise first. Once we clarify what EDT says exactly, we will also be in a position to see why it is incompatible with the heuristics-model.

EDT is understood throughout this paper to be the view that emotions are the highest court of appeal when axiological properties are at issue. This view seems to be explicitly endorsed by Hume, for example, in the quote already cited in the introduction. ${ }^{17}$ More generally, advocates of EDT assert all of the following: (i) the experience of a certain emotion furnishes a prima facie justification for claims about axiological properties, (ii) there may be reasons defeating such prima facie emotional justification (such as the presence of factors obscuring the normal operation of our emotional sensibilities), but (iii) the ultima facie justifiability of such axiological claims will be settled by appeal to affective responses (see for example Wiggins 1987; Tappolet 2000; D’Arms \& Jacobson 2011).

15 Russell (1992) argues persuasively for the need to distinguish between justificatory requirements for token emotional responses as opposed to justificatory requirements (if any) for general emotional dispositions.

16 As Damasio would, once again, agree: "At their best, feelings point us in the proper direction, take us to the appropriate place in a decision-making space, where we may put the instruments of logic to good use." Damasio 1994, xiii.

17 "The final sentence [...] which pronounces characters and actions amiable or odious [...] depends on some internal sense or feeling." [my italics]. 
What this view amounts to can be best seen when a proposition about some axiological property is contested, that is, when we ask questions such as "is this act really courageous?" or "is this movie really amusing?" and so on. As can be seen from (i)-(iii), advocates of EDT do not believe that emotional reactions are guaranteed to get matters right. It is granted by them that "fundamental evaluative disputes" (D'Arms and Jacobson 2011, 605) can and will arise because we may have good reasons to question the reliability and trustworthiness of our emotional reactions. Still, at the end of the day these fundamental evaluative disputes will be resolved by consulting our relevant emotional reactions.

Now, in order to see the implications of the heuristics-model with regard to the epistemology of value, it is helpful to make it clear that the heuristics-model does not take issue with claims (i) and (ii). In fact, the heuristics-model offers a robust and empirically supported explanation why we turn in many situations to our emotions to reach an initial evaluative assessment: heuristics are "fast and frugal". Given how well heuristics perform in most situations we are likely to encounter, we have good prima facie reasons to trust and rely on the normative cues they deliver. The heuristics-model also recognizes the presence of factors that can adversely influence the performance of heuristics. There is no space to discuss these matters here, but these factors show a remarkable overlap with the reasons (sometimes also referred to as "defeaters") sentimentalists identify for not trusting the deliverances of our sentiments on certain occasions (see esp. Tappolet 2000, 216-223 and D’Arms and Jacobson 2011, 598-605).

Therefore, the heuristics-model is not incompatible with the view that emotions could be statistically more likely to be correct than evaluative beliefs. As noted, it has been found that in certain situations heuristics significantly outperform reflective thinking. It is an empirical and contingent matter - also depending on one's profession, cultural background, and so on - how often one is likely to encounter situations in which affective heuristics will serve one well and how often one ends up in those special situations when the heuristic will mislead.

It is only claim (iii) made by advocates of EDT that we have to reject if we accept the heuristics-model. However, this difference is crucial. The heuristics-model entails that the normative cues emotions deliver are always at best prima facie justifications for our axiological beliefs. To repeat, this should not worry us all that much as in most situations heuristics attributes overlap with genuine axiological properties and therefore the heuristic will yield the right result. But not always. Moreover, since heuristics employ the 
mechanism of substitution as explained in Section 2 above, the divergence will not be contingent but rather systematic and predictable. That is, in situations in which affective heuristics do not perform well or do not perform at all, emotions will be systematically “more prone to forms and error and confusion" (pace D’Arms and Jacobson 2011, 611) than axiological beliefs arrived at by means of reflective thinking. The next section takes a closer look at those types of cases where heuristics break down.

\section{When heuristics break down}

Let us now consider celebrated cases from the philosophy of emotions literature: recalcitrant emotions, emotional responses (or the lack thereof) by agents complicit in collective wrongdoing, and emotional reactions in moral conflicts and dilemmas. I offer this discussion in support of both the negative and positive objectives of the paper. As regards the positive objective, I hope to demonstrate that the heuristicsmodel provides a good explanation of the observable peculiarities of our emotional responses in these situations. As regards the negative objective, I hope to show that these cases also cast serious doubt on EDT in the highest-court-of-appeal sense clarified in the previous section. Finally, this discussion will also make it transparent why EDT in this sense is incompatible with the heuristics-model.

The common denominator among the cases to be discussed is that the typical emotional reactions we experience in them offer little or no guidance as to how we should evaluate them. We have good reason to mistrust the deliverances of our emotional responses (Section 5.1), or else our emotional responses are either absent or weak (Section 5.2) or too confused (Section 5.3) to be of any epistemic assistance in our efforts to discover or learn about the axiological properties instantiated in those cases. This is why these cases are important to undermining EDT. At the same time, they also corroborate the heuristics-model. I will argue that this is because in all of these cases we come across enviroments in which affective heuristics cannot function well. The breakdown of affective heuristics well explains the unusual patterns of emotional reactions in them.

But if the deliverances of our emotional sensibilities cannot be relied upon precisely when evaluation is at its most difficult, then EDT as the highest-court-of-appeal view of emotions has little bite. Moreover, if emotional sensibilities founder precisely when we would most need them, then we have reason to be more cautious about what 
justificatory role we assign to them in less difficult cases as well. If so, then the lesson drawn from hard cases can be generalized to cases in which emotional responses and reflective evaluations converge (Section 5.4).

\subsection{Recalcitrance}

Recalcitrant emotions persist despite the subject's judgment that there is no reason justifying the emotion. Hume's original example is of someone who continues to be afraid of falling despite knowing that she is safe (Hume 1974). The phenomenon of recalcitrance is typically used to argue against judgmentalism about emotions (so for example in D'Arms \& Jacobson 2003 and Döring 2010).

Let us first see how the heuristics-model explains this phenomenon. In terms of this model, the recalcitrant emotion persists because the affective heuristic remains active despite its irrelevance in the given situation. What we are dealing with here is another case of an overgeneralized heuristic that fails to perform outside its customary and adaptive environment. The emotional reaction continues to function as a source of information despite the fact that that information, as all agree, has no basis in reality. ${ }^{18}$ So the misfiring of the affective heuristic in cases of recalcitrant emotions is comparable to the breakdown of non-affective heuristics in other contexts (described in Sunstein 2003; Sunstein 2005; Kahneman 2011).

In addition, the heuristics-model explains why the emotional response occurs despite it being recognizably inadequate in the given situation. As we have seen emotional responses are evolutionarily tailored and neurophysiologically enabled to deliver information about familiar environments without requiring extensive cognitive-evaluative activity. In short, the survival value of emotions as heuristics lies in delivering such information spontaneously and almost automatically. Emotions become recalcitrant because the adaptive value of relying on emotions as a source of information outweighs the costs of the occasional misperformance of this resource in situations requiring reflective analysis (or at least this was the case at the decisive stage of our evolutionary history when our basic emotional capacities developed).

18 And thus we have another demonstration of the general claim repeatedly made in Kahneman 2011 (364, etc.) that the performance of the non-reflective cognitive "System 1", of which affective heuristics form an important part, is not "reality-bound." 
As noted above, the phenomenon of recalcitrance is an important weapon in the arsenal of anti-judgmentalists. If emotions can persist in spite of one's evaluative judgments, then such judgments can hardly be said to be constitutive of emotions. It is more plausible to construe emotions as "the product of some discrete evaluative mechanism" (D'Arms \& Jacobson 2003, 141). The suggestion made here to use the heuristics-model to explain the phenomenon of recalcitrance is in partial agreement with such alternative accounts of recalcitrance. But there are a number of important differences.

The first advantage of the present suggestion is that it offers an empirically-plausible solution without having to commit itself to either the judgmentalist or anti-judgmentalist side in the debate whether evaluative judgments are constitutive of emotions or not (see Section 3.1). Another advantage is that one need not limit the phenomenon of recalcitrance to only a restricted range of basic emotions (e.g., fear, anger). Arguably, such a limitation is implausible because even complex and idiosyncratic emotions can be recalcitrant. Thus secondary emotions such as recalcitrant homesickness, tenure-rage, or religious awe are quite possible, and I think not uncommon (pace D'Arms \& Jacobson 2003, 142). ${ }^{19}$ The heuristics-model can handle cases of recalcitrance for secondary emotions as well construing them as sources of evaluative information.

Thirdly, unlike some of the alternative accounts of recalcitrance, which ignore this point, the heuristics-model explicitly recognizes the fact that recalcitrant emotions can make us believe and do the right thing, and so it can be rational to rely on them, even against the contradictory evaluative judgment. This can happen because the evaluative judgment can be mistaken and can point one in the wrong direction. Huckleberry Finn's ultimate refusal to turn his friend Jim in, despite his best judgment to the contrary, is a vivid illustration of this possibility (Döring 2010).

But the most important issue is that the phenomenon of recalcitrant emotions should also give pause to advocates of the EDT. If emotions can persist despite our best judgment that they are wholly unjustified in some cases, then it is hard to see on what grounds emotions should be stipulated to be the highest court of appeal in matters axiological. In my view, this point is not sufficiently appreciated by anti-judgmentalist advocates of EDT. Quite simply, the difficulty for these authors is that they want to be able to rule out some

19 The reason for the confusion on this point in D'Arms \& Jacobson 2003 (an article to which this paper is of course very much indebted otherwise) is that they misdescribe the relevant belief. For example, the relevant belief in the case of homesickness is not that one is "really at home", but rather that it is "best to be at home" or some other evaluative belief like that. In other words, there is confusion here between the "material object" and the "formal object" of the emotion (see Mulligan 2010,478f. on this distinction). Once the confusion is cleared up, it is easy to see that recalcitrant homesickness is very much possible. 
recalcitrant emotions as inappropriate, but it seems hard to do this without ultimately invoking reflective judgments to settle matters of justifiability. ${ }^{20}$ The crucial issue is not whether such judgments necessarily form part of emotional responses, nor whether these emotional responses can be right (which of course they can be), but rather where we should turn to when the appropriateness of such responses is in question.

My interim conclusion drawn from the discussion of recalcitrance is that the heuristicsmodel is capable of explaining both how emotional responses can so often be right: affective heuristics tend to work well in familiar contexts. At the same time, unlike the anti-judgmentalist sentimentalist framework, this model does not deny us the resources to assess the appropriateness of such affective responses: the deliverances of affective heuristics are monitored and corrected by reflective thought.

\subsection{Collective action}

This interim conclusion is further supported by those cases which are normatively and morally significant but tend to be marked by the universal (or nearly universal) absence of emotional reactions. Individual reactions of agents complicit in collectively brought about harms present an important type of example. Thus in many cases which involve harm due to the aggregation of actions by several people - think of environmental pollution, multinational corporations or intergovernmental organizations - contributors tend to experience no guilt feelings. Or at least, the guilt they experience is much less intense (see Kutz 2000) than if they had caused the same kind of harm alone or in small groups.

Now note, first, that the heuristics-model can offer a plausible explanation of the changing pattern of guilt feelings in such cases of collective action, that is, why guilt tends to be less intense or entirely absent. Given its evolutionary origins and biological underpinnings discussed earlier, we can expect the guilt-heuristics to be geared primarily towards one's own actions in relatively uncomplicated, familiar situations. These tend to involve only a few and evaluatively salient features, thus paradigmatically, a single action of visible impact and short duration by one agent causing harm to one or few victims.

And this is indeed what seems to happen in cases in which a large number of people contribute to bringing about some collective harm. The more distant the actual situation is from the simple paradigm, the more likely it becomes that participants will feel no guilt at

20 Which is precisely what D'Arms and Jacobson do for example, see D'Arms \& Jacobson 2003, 144-145. 
all, or their guilt will be less intense. That is, the higher the number of agents participating in the collective action, the longer the duration of the action, the less visible and physically proximate the impact, and the more distributed the harm over many victims, the less likely are participating agents to experience guilt. ${ }^{21}$

On the other hand, this finding about complicitous guilt (or the lack of it) casts further doubt on EDT. We typically believe that contribution to collectively brought about harms is often culpable and in many cases as bad as individual wrongdoing. Both consequentialist (Parfit 1984) and non-consequentialist (Kutz 2000) authors agree on this point. In any case, although there are divergent views on the exact degree and source of culpability in such cases, it is generally agreed that culpability does not correlate with the kind of factors listed above such as duration, physically proximity, etc. which, however, significantly impact on whether guilt is experienced or not. If so, then once again we have a morally significant type of situation in which the presence/absence and intensity of an emotion fails to be an indicator which we could rely on when evaluating the relevant situation. ${ }^{22}$

\subsection{Hard cases}

I now want to argue that EDT is inconsistent with our emotional responses in situations of moral conflict and related problematic cases. At the same time, the heuristics-model provides a reasonable explanation of typical emotional response patterns in such situations.

Consider Sophie's Choice (Greenspan 1983) which many argue is the purest example of a genuine moral dilemma. The basic set up of the case is as follows. Sophie receives this offer: "choose between your two children, otherwise both will be killed". Sophie chooses one of her children and so only one child is killed.

21 This prediction is consistent with the role of affect observed in other contexts as well. Take, for example, the explanation of the so-called "mere exposure effect", that is, an account of why mere repetition of a stimulus generates mildly positive affect towards that stimulus. As Robert Zajonc, who discovered this effect, puts it: "The consequences of repeated exposures benefit the organism in its relations to the immediate animate and inanimate environment." (quoted in Kahneman 2011, 67 - my italics).

22 Further support for this conclusion could come from cases of vicarious feelings of guilt as when a citizen of Germany feels guilty about the Holocaust today. A possible complication is that these may well turn out to be feelings of shame rather than guilt - and such shame, some people would say (in my view incorrectly), is appropriate while guilt is not. In any case, it has been argued that the basis for such emotions felt on behalf of others is a perception of similarity between the other person and oneself and a resulting sense of solidarity (see Feinberg 1970, 64). If this is correct, then the phenomenon of vicarious emotions could also be read as confirming the heuristics-model of emotions: once again, what prompts the emotion are morally-speaking contingent factors such as physical proximity, similarity and subjective salience from the first-person perspective. 
Few would deny that Sophie, and most people in Sophie's place, will feel something more or less resembling ordinary guilt feelings. However, we can also expect Sophie to experience intense inner conflict and persistent doubt (McConnell 1978). Again, I think the heuristicsmodel offers a good explanation of typical emotional responses in such situations including the experience of moral doubt and inner conflict which is likely to manifest itself simultaneously with the emotion.

As with the phenomenon of recalcitrance, the basic idea is once again that the affective heuristics has not been "designed" to deal with such extreme and difficult cases such as Sophie's. Although well outside its familiar environment, the affective heuristic nevertheless continues to function as an information channel. In fact, given how deeply the situation must affect Sophie personally as a mother and as a moral agent, it is not surprising that the affective response will also be particularly intense. The heuristicsmodel predicts that what happens in cases like Sophie's is that the continued reliance on guilt as an epistemic resource used to evaluate her actions conflicts with her nonaffectively-based beliefs regarding the case. The presence of guilt(-like) feelings continues to suggest to her that she has done something culpably wrong, but she will also entertain beliefs conflicting with the affectively-based epistemic input.

At the same time, the peculiar character of emotional responses in moral conflicts of this kind creates further difficulties for EDT. The first difficulty is that it remains fundamentally ambiguous what Sophie really feels - both to herself and to external observers. Tellingly, even friends of moral dilemmas sometimes speak of Sophie's emotional response as guilt, and sometimes as regret. ${ }^{23}$

Nor is Sophie's an isolated case. There are many other examples which lack the special dilemmatic structure of Sophie's choice but pose the same kind of challenge. Consider, for example, the case of the Faultless Truck Driver, that is, the driver who runs over a child through absolutely no fault of his (Williams 1976). Bernard Williams says that this driver will feel differently from any spectator. This is probably true in most cases and it is probable too that the emotion will feel like something similar to guilt. However, once again, it is unclear what the truck driver will feel exactly, but quite clear that the truck driver's feelings will be conflicted and accompanied by doubt.

23 Compare and contrast Williams 1973a and Marcus 1980, and see also Gowans 1987, 15. Note that McConnell (1978), an outspoken opponent of moral dilemmas, also describes the relevant kind of emotional experience in a moral dilemma as regret. The relevant emotion is sometimes also labelled as remorse, but in this context remorse is probably meant to be synonymous with guilt. 
The problem in these cases is that the emotional response cannot be used as evidence in the evaluation of the relevant situation because one could only rely on the emotional response if one knew how to classify the emotion. But this remains unclear both from the firstperson and third-person perspectives. My point of course is not that these situations cannot be evaluated (if that were the case, EDT would be false anyway). Rather, the point is that focusing on the emotional responses will not deliver the answers to these questions.

Second, whatever emotional responses these situations have given rise to, these emotions are characteristically accompanied by doubt and inner conflict as just noted. The basic problem then is: how could such amorphous, conflicted and doubt-ridden emotions provide useful information regarding the evaluative properties of the relevant situations? ${ }^{24}$ But if the deliverances of our emotional sensibilities cannot be relied upon precisely when evaluation is at its most difficult, then why should we hang onto a view of emotional responses as capable of settling evaluative disputes?

Well, perhaps the cases just discussed are just too hard or too special to warrant general conclusions. So let us turn to less difficult situations.

\subsection{Central cases}

What about central cases then? Do they support my skepticism about EDT and my optimism about the heuristics-model?

After all, I have granted that in most familiar environments affective heuristics do converge with the non-affective assessment of the situation. It may therefore be objected that the cases discussed above are only marginally relevant to assessing how well emotional responses track the presence of evaluative properties. For one thing, some of the problem cases mentioned above are artificially constructed and are very unlikely to occur in real life. Furthermore, it may be objected that nobody who subscribes to EDT has ever claimed that emotions would always be absolutely reliable, let alone infallible, and never fuzzy or equivocal.

24 Incidentally, this worry looms large for friends of moral dilemmas as well, i.e., for those who think that there can be situations in which no course of action is all-things-considered justifiable. What is perhaps the most influential argument for the existence of moral dilemmas is at bottom sentimentalist and runs as follows: since Sophie would feel guilt appropriately no matter which course of action she were to choose (sacrificing one child, or the other, or not accepting the offer letting both die), she is in a moral dilemma (see Williams 1973a, Marcus 1980). However, this emotion-based argument for moral dilemmas only goes through provided that what Sophie feels really is guilt. But how can we be sure that this is indeed the case? 
In response to this objection, it should be noted first of all that the plausibility of the heuristics-model is not undermined by the convergence between affective heuristics and reflective judgments in "easy" cases. Quite the contrary. The convergence between evaluative information produced by affective heuristics and straightforward evaluative judgments is exactly what the heuristics-model predicts. To repeat, affective heuristics frequently "get it right", especially when operating in their natural habitats.

The second part of the response to the objection consists in questioning the dialectical significance of central cases. It is questionable what we can learn from central cases precisely because they are marked by the convergence of emotional and reflective responses. Hard cases serve a crucial methodological purpose because they are essential to teasing out divergences between heuristics-based assessments and reflective, controlled evaluations. $^{25}$

No doubt, many will find this response wanting. The most pressing worry is that this response underestimates the significance of central cases. Granted, in the special situations discussed earlier emotions are not infallible and perhaps not even moderately reliable guides to the presence and character of axiological properties. But this only shows, so the complaint, that we have to add certain qualifications to EDT. These qualifications are familiar from dispositionalist theories of secondary qualities. Thus we should perhaps read EDT as saying something like this: under normal circumstances and for normal subjects emotions will be the highest court of appeal for the justification of axiological claims (call this version ceteris paribus EDT).

This qualification, however, cannot rescue EDT. For one thing, not all the examples discussed above are exotic or rare. For instance, the phenomenon of changing emotional response patterns in cases of complicity in collective harms discussed in Section 5.2 above is a very common occurrence. Apart from the issue of frequency, it should also be noted that there appears to be nothing abnormal about the agents concerned even in the special cases discussed in Sections 5.1 and 5.3. People tend to agree, for example, that it is normal for Sophie or the truck driver to feel conflicted and confused. By the same token, emotional recalcitrance is an ordinary occurrence that does not indicate a malfunctioning of one's emotional sensibilities. Quite the contrary, emotional recalcitrance is a product of the normal functioning of the neurophysiology of the affective system as we have seen earlier.

25 A positive implication of all this is that we can continue to treat hard cases as important for moral theorizing. Thus Sunstein (2005) is wrong to discount exotic cases such as Sophie's Choice as largely irrelevant to ethics. 
To see what is at stake here we can draw an analogy between cases where our emotional sensibilities fail to guide our evaluations and perceptual illusions (e.g., the stick appearing bent in water). The latter are of course predictable and systematic and will be experienced by normal subjects under ordinary circumstances. But of course the fact that the stick is perceived to be bent by normal subjects under ordinary circumstances should not be as justification for claims about genuine properties of the stick. By the same token, only because some emotional response is typically displayed by "normal" subjects under "normal circumstances" that emotional response should not play a special role in the justification of claims about axiological properties. ${ }^{26}$

To see what is at stake here, consider this last bit of empirical evidence. In a recent experiment a marked correlation was found between the endorsement of utilitarian solutions to situations of moral conflict such as the Trolley Problem, on the one hand, and a set of abnormal psychological traits such as emotionally callousness and psychopathic personality, on the other (Bartels \& Pizarro 2011). If the ceteris paribus version of EDT was correct, we would have to take this experiment as favouring a non-utilitarian moral theory.

Needless to say, for all we know, utilitarianism may be the wrong ethical theory after all. If so, then the experiment could indeed be cited as evidence that moral emotions converge with correct ethical judgments - at least most of the time. But the decisive question as regards the ceteris paribus version of EDT is another: can the experiment be cited as evidence that utilitarianism is the wrong ethical theory? Arguing in this order would surely be mistaken.

To summarize, even in central cases heuristics work by substitution. So the decisive question is how to explain convergence in central cases. If the heuristics-model is right, then the explanation of convergence is that heuristic attributes and target attributes coincide in central cases. This is not surprising: after all, this is precisely why heuristics can be evolutionarily adaptive. At the same time, heuristics are triggered by an ersatz property even in these cases. Consequently, heuristics can only yield approximations. The divergence between the heuristic-based approximations and reflective thought processes will be exposed by focusing on the kinds of hard cases discussed earlier.

26 Unless of course we are prepared to give up realism about axiological properties. But that is not the way sentimentalists in this paper want to go (see explicitly Tappolet 2000, 5). 


\section{Conclusion}

Bernard Williams complained that contemporary moral philosophy had too little to say about the emotions (Williams 1973b, 207). First, there would be more to say about the relevance of emotions to the adequate analysis of moral concepts. And second, there would be more to say too about emotions themselves being potential objects of moral assessment. In closing, I want to indicate that despite superficial appearances the model is actually amenable to meeting these two Williamsian desiderata.

Even if emotions are heuristics, it is perfectly reasonable to say that "one ought to feel so and so" in a given situation, or even that anyone "who is not capable of a certain kind of emotion ought to be despised". As I have emphasized throughout this paper, the fact that emotions function as heuristics does not mean that they are not useful. Indeed, in many cases they are indispensable. Emotions can alert us to salient evaluative features of a situation before reflective assessment could even begin. Attempting to "think it through" may be counterproductive or even disastrous.

It also remains true that some moral concepts are bound up with emotions. I cannot address this issue in any detail here, but consider guilt or blame by way of example. These emotions are, among other things, unpleasant, sometimes tormenting. Consequently, it is for first-order moral norms to settle under what conditions the torment of guilt or blame can be undeserved.

I conclude that it would be wrong to dispute that emotions are an important source of knowledge about value. Affective heuristics are often useful and sometimes indispensable. What I have objected to is the idea that emotions would constitute an epistemically superior or even privileged source of knowledge about value in the sense that emotions could function as the highest court of appeal to settle the justifiability of axiological claims. 


\section{References}

Bartels, Daniel M, \& Pizarro, David A (2011) The mismeasure of morals: antisocial personality traits predict utilitarian responses to moral dilemmas. Cogn 121:154-161

Bartsch, Karen \& Wright, Jennifer C (2005) Towards an intuitionist account of moral development. Behav Brain Sci 28:546-547

Crane, Tim (1992) The nonconceptual content of experience. In: Crane, T (ed) The contents of experience: essays on perception. Cambridge: Cambridge University Press, pp 136-157

Czerlinski, Jean, Gigerenzer, Gerd, \& Goldstein, Daniel G (1999) How good are simple heuristics? In: Gigerenzer, Gerd, Todd, Peter M. \& the ABC Research Group (ed): Simple heuristics that make us smart, New York: Oxford University Press, pp 97-118

Damasio, Antonio R. (1994) Descartes' error. London, Picador

Damasio, Antonio R. (1995) Toward a neurobiology of emotion and feeling: Operational concepts and hypotheses. Neurosci 1:19-25

D’Arms, Justin (2005) Two arguments for sentimentalism. Phil Issues 15:1-21

D’Arms, Justin \& Jacobson, Daniel (2000) Sentiment and value. Ethics 110:722-748

D’Arms, Justin \& Jacobson, Daniel (2003) The significance of recalcitrant emotion (or, antiquasijudgmentalism). In: Hatzimoysis A (ed) Philosophy and the emotions, Cambridge: Cambridge University Press, pp 127-146

D'Arms, Justin \& Jacobson, Daniel (2010) Demystifying sensibilities: sentimental values and the instability of affect. In: Goldie, P (ed) The Oxford Handbook of Philosophy of Emotion, Oxford: Oxford University Press, pp 585-613

De Sousa, Ronald (2010) The mind's Bermuda Triangle: philosophy of emotions and empirical science. In: Goldie, P (ed) The Oxford Handbook of Philosophy of Emotion, Oxford: Oxford University Press, pp 95-117

Döring, Sabine A. (2010) Why be emotional? In: Goldie, P (ed) The Oxford handbook of philosophy of emotion, Oxford: Oxford University Press, pp 283-301

Ekman, Paul (1992) An argument for basic emotions. Cogn and Emot 6:169-200

Feinberg, Joel (1970) Collective responsibility. In: May, L \& Hoffman, S (ed) Collective responsibility, Lanham: Rowman \& Littlefield, pp 53-76

Finucane, Melissa L, Alhakami, Ali, Slovic, Paul, \& Johnson, Stephen M (2000) The affect heuristic in judgments of risks and benefits. J Behav Decis Mak 13:1-17

Gibbard, Allan (1990) Wise choices, apt feelings: a theory of normative judgment. Cambridge, MA: Harvard University Press

Gigerenzer, Gerd \& Goldstein, Daniel G (1996) Reasoning the fast and frugal way: models of bounded rationality. Psych Rev 103:650-669.

Gigerenzer, Gerd, Todd, Peter M. \& the ABC Research Group (1999) Simple heuristics that make us smart. New York: Oxford University Press 
Greenspan, Patricia S. (1983) Moral dilemmas and guilt. Phil Stud 43:117-125

Haidt, Jonathan (2001) The emotional dog and its rational tail: A social intuitionist approach to moral judgment. Psych Rev 108:814-834

Hume, David (1973) Enquiries concerning human understanding and concerning the principles of morals (1777), L. A. Selby-Bigge and P. H. Nidditch (ed). Oxford: Clarendon Press

Hume, David (1974) A treatise of human nature (1739-40), L. A. Selby-Bigge and P. H. Nidditch (ed). Oxford: Clarendon Press

Hurley, Susan (2005) Social heuristics that make us smarter. Phil Psych 18:585-612

Kahneman, Daniel (2011) Thinking, fast and slow. London: Penguin

Kahneman, Daniel \& Frederick, Shane (2002) Representativeness revisited: Attribute substitution in intuitive judgment. In: In: Gilovich, T, Griffin, D and Kahneman D (ed) Heuristics of intuitive judgment: extensions and applications, New York: Cambridge University Press, pp 49-81

Kunst-Wilson, William R. \& Zajonc, Robert B. (1980) Affective discrimination of stimuli that cannot be recognized. Sci 207:557-558.

Kutz, Christopher (2000) Complicity. Cambridge: Cambridge University Press

Lazarus, Richard S (1984) On the primacy of cognition. Am Psych 39:124-129

LeDoux, Joseph E (1995) Emotion: clues from the brain. Ann Rev Psych 46:209-235

Marcus, Ruth B (1980) Moral dilemmas and consistency. J Phil 77:121-136

McConnell, Terence (1978) Moral dilemmas and consistency in ethics. Can J Phil 8:269-287

Mulligan, Kevin (2010) Emotions and values. In: Goldie, P (ed) The Oxford handbook of philosophy of emotion, Oxford: Oxford University Press, pp 475-500

Murphy, Sheila T \& Zajonc, Robert B (1993) Affect, cognition, and awareness: affective priming with optimal and suboptimal stimulus exposures. J Personal Soc Psych 64:723-739

Nussbaum, Martha (2001) Upheavals of thought: the intelligence of the emotions.

Cambridge: Cambridge University Press

Parfit, Derek (1984) Reasons and persons. Oxford: Oxford University Press

Perler, Dominik (2011) Transformation der Gefühle. Philosophische Emotionstheorien.

Frankfurt a.M.: S. Fischer

Prinz, Jesse (2004) Gut reactions: a perceptual theory of emotions. Oxford: Oxford University Press

Russell, Paul (1992) Strawson's way of naturalizing responsibility. Ethics 102:287-302

Schwarz, Norbert \& Clore, Gerald L (1983) Mood, misattribution, and judgments of wellbeing: informative and directive functions of affective states. J Personal Soc Psych 45:513-523

Slovic, Paul, Finucane, Melissa L, Peters, Ellen, MacGregor, Donald G (2002) The affect heuristic. In: Gilovich, T, Griffin, D and Kahneman, D (ed) Heuristics of intuitive judgment: extensions and applications, New York: Cambridge University Press, pp 397-420. 
Sunstein, Cass R. (2003) Hazardous heuristics. Univ Chic Law Rev 70:751-782

Sunstein, Cass R. (2005) Moral heuristics. Behav Brain Sci 28:531-573.

Tooby, John \& Cosmides, Leda (1990) The past explains the present: emotional adaptations and the structure of ancestral environment. Ethol Sociobiol 11:375-424

Tappolet, Christine (2000) Émotions et valeurs. Paris: Presses Universitaires de France

Weber, Elke U \& Ancker, Jessica S (2005) Towards a taxonomy of modes of moral decisionmaking. Behav Brain Sci 28:563-564

Wiggins, David (1987) A sensible subjectivism? In: Wiggins, David: Needs, values, truth. Oxford: Blackwell, pp 185-214

Williams, Bernard (1973a) Ethical consistency. In: Williams, Bernard: Problems of the self. Cambridge: Cambridge University Press, pp 166-186

Williams, Bernard (1973b) Morality and the emotions In: Williams, Bernard: Problems of the self. Cambridge: Cambridge University Press, pp 207-229

Williams, Bernard (1976) Moral luck. In: Williams, Bernard: Moral luck. Cambridge: Cambridge University Press, pp 20-39.

Zajonc, Robert B (1980) Feeling and thinking: preferences need no inferences. Am Psych $35: 151-175$ 